\title{
The diagnosis and management of nerve injury during endodontic treatment
}

\author{
Eyal Rosen
}

\begin{abstract}
Background: Nerve injury and an ensuing altered sensation following endodontic treatment is an infrequent and severe complication, which may lead to longstanding disability and may have substantial adverse effects on the patient's quality of life. This review is aimed at providing the practitioner with the knowledge and useful means to diagnose and manage nerve injury when performing endodontic treatments.

Conclusion: Vigorous preventive measures and a timely mannered management approach are the most proficient measures to reduce the risk of endodontic treatment related nerve injuries and to prevent long-lasting impairment. The diagnosis of a nerve injury requires a combination of a thorough anamnesis, a proper clinical evaluation, and an adjunct radiographic evaluation when indicated. Early intervention by the prescription of anti-inflammatory drugs may be beneficial. In certain persistent cases, modern endodontic surgery may enable a minimally invasive and highly accurate surgical procedure, and with adequate case selection, may provide a predictable outcome and allow the preservation of the tooth.
\end{abstract}

Keywords: Endodontic treatment, Nerve injury, Altered sensation, Diagnosis, Management

\section{Introduction}

Altered sensation due to a nerve injury is an infrequent and severe complication of endodontic treatments (Pogrel, 2017; Escoda-Francoli et al., 2007; Grotz et al., 1998; Rosen, 2014; Rosen et al., 2016). Practically all endodontic procedures, such as local anesthesia administration (Garisto et al., 2010), root canal preparation and irrigation (Guivarc'h et al., 2017), root canal filling (Rosen et al., 2016), and surgical endodontic treatments (Kim \& Kratchman, 2006; Moiseiwitsch, 1995; Alves et al., 2014), that are performed in the vicinity of trigeminal nerve branches may trigger nerve injury (Rosen et al., 2016; Yatsuhashi et al., 2003). Many non-endodonticrelated entities such as infectious diseases, trauma, tumors, or idiopathic diseases have also been suggested as possible origins of altered sensation of trigeminal nerve branches (Divya et al., 2010), and should be regarded as a differential diagnosis for endodontic treatment related nerve injury (Rosen, 2014; Gallas-Torreira et al., 2003; Givol et al., 2011; Pogrel, 2007; Tilotta-Yasukawa et al., 2006).

Inferior alveolar and mental nerve injuries have been frequently reported in second mandibular molars and

Correspondence: dr.eyalrosen@gmail.com

Maurice and Gabriela Goldschleger School of Dental Medicine, Department of Endodontology, Tel Aviv University, Tel Aviv, Israel mandibular premolars (Tsesis et al., 2014; Chong et al., 2017), but also in other mandibular teeth (Rosen et al., 2017). Nerve injuries were also often reported following local anesthetic administration for endodontic treatment purposes (Pogrel, 2017; Rosen, 2014; Garisto et al., 2010; Pogrel et al., 2011).

The risk of nerve injury during endodontic treatments is a matter of huge concern, and some diagnostic (Bornstein et al., 2011; Kamburoglu et al., 2009; Kim et al., 2010; Kovisto et al., 2011; Simonton et al., 2009) and treatment approaches (Kim \& Kratchman, 2006; Moiseiwitsch, 1995) have been suggested in order to avoid nerve injury during endodontic treatments (Rosen, 2014; Kim \& Kratchman, 2006). Nevertheless, the existing literature evaluating the prevalence and the clinical manifestation of endodontic treatment related nerve injuries is insufficient, thus our understanding of its clinical and medico-legal aspects is limited (Pogrel, 2017; Rosen, 2014; Kim \& Kratchman, 2006; Givol et al., 2011; Pogrel, 2007).

This manuscript will review the diagnosis and management of endodontic-related nerve injuries, and aims to provide the practitioner with the knowledge and useful means to diagnose and manage nerve injury when performing endodontic treatments. 


\section{Review}

Mechanical nerve injuries during endodontic treatment may be classified, based on the time course and the potential sensory recovery into: Neuropraxia (cases in which there is a brief altered sensation); Axonotmesis (partial damage to the nerve fibers that may fully recover within 212 months); and Neurotmesis (a nerve that has been entirely cut, with poor prognosis for recovery) (Rosen, 2014; Juodzbalys et al., 2011; Seddon, 1942).

The clinical manifestations of endodontic treatment related nerve injuries may vary, and include a mixture of both subjective complaints of the patient and objective neurological signs. To simplify the clinical classification, most cases may be categorized as Anesthesia (insensitivity to stimulations), Paresthesia (a sensation such as burning or partial numbness), or Hyperesthesia (increased sensitivity to stimulation). These altered sensations are dynamic and may often change along time following the injury (Escoda-Francoli et al., 2007; Rosen, 2014; Garisto et al., 2010; Gallas-Torreira et al., 2003; Givol et al., 2011; Pogrel, 2007; Seddon, 1942), potentially affecting the lips, teeth, gingiva, tongue, or the adjacent mucosa and skin (Rosen, 2014; Hillerup \& Jensen, 2006).

Several possible risk factors for nerve injury related to endodontic treatments have been reported, including the tooth location (Rosen, 2014; Rosen et al., 2016; Tilotta-Yasukawa et al., 2006; Pogrel et al., 2011) and the patient's gender (Bjorndal \& Reit, 2008; Givol et al., 2010; Givol et al., 2002). Acknowledging the possible risk factors for nerve injury may be beneficial for prevention and diagnosis of such injuries (Pogrel, 2017; Rosen, 2014; Pogrel et al., 2011).

Furthermore, since most routine endodontic procedures may lead to nerve injury during the treatment (Pogrel, 2017; Rosen, 2014; Kim \& Kratchman, 2006; Moiseiwitsch, 1995), the application of preventative measures before and during the treatment (Rosen, 2014; Pogrel et al., 2011) is the most efficient way to avoid this complication. However, when this severe complication occurs, an accurate and timely mannered diagnosis is important for enabling efficient management, and for improving the prospects for recovery (Grotz et al., 1998; Rosen, 2014; Garisto et al., 2010; Yatsuhashi et al., 2003; Gallas-Torreira et al., 2003; Pogrel, 2007; Givol et al., 2010; Givol et al., 2002; Chaushu et al., 2002; Scolozzi et al., 2004; Seddon et al., 1943).

\section{Diagnosis of endodontic treatment-related nerve injury}

The clinical manifestation may vary depending on the specific injury mechanism. Generally, the diagnosis of a nerve injury requires a combination of a thorough anamnesis, a proper clinical evaluation, and an adjunct radiographic evaluation when indicated. Periapical radiography is the principal radiographic modality used for endodontic diagnosis, treatment planning, and for the management of endodontic complications (Rosen, 2014;
Pogrel et al., 2011). In certain cases, periapical radiography alone may be clinically limited for the diagnosis and management of a suspected nerve injury, by the fact that the information is rendered in just two dimensions (Rosen, 2014; Kim \& Kratchman, 2006; Moiseiwitsch, 1995; Pogrel et al., 2011; Bornstein et al., 2011; Kim et al., 2010; Kovisto et al., 2011). For example the diagnosis of potential anatomical abnormalities such as mandibular accessory canals may require the use of computed tomography scans, such as cone-beam computed tomography $(\mathrm{CBCT})$, in order to enable the visualization of the area of interest in three dimensions (Rosen, 2014; Pogrel et al., 2011; Patel, 2009), and in order to enable the planning of a more adequate treatment approach (Rosen, 2014; Rosen et al., 2017; Rosen et al., 2017). However, the decision whether to use CBCT scan should be justified on an individual basis (Rosen et al., 2017; Rosen et al., 2015).

Since most of the endodontic procedures are performed under local anesthesia (Rosen, 2014; Pogrel et al., 2011), the symptoms of nerve injuries will usually be evident only following the treatment, when the local anesthesia effect wears out. Nevertheless, when a nerve injury occurs during the treatment, early intervention is important (Rosen et al., 2016). Thus, following the treatment, the practitioner needs to be ready to detect any possible signs of altered sensation (Givol et al., 2011; Pogrel, 2007; Juodzbalys et al., 2011; Givol et al., 2010).

Early symptoms that may suggest a possible nerve injury include neurosensory alterations, such as paresthesia or acute pain during or following the treatment (Froes et al., 2009). If a nerve injury is suspected, a timely mannered management approach is advised in order to define the exact sensory disturbance; quantify the sensory disturbance; determine management needs; and monitor recovery (Grotz et al., 1998; Rosen, 2014; Yatsuhashi et al., 2003; Pogrel, 2007; Juodzbalys et al., 2011; Seddon, 1942; Scolozzi et al., 2004; Seddon et al., 1943).

First, the clinician should perform a neurosensory evaluation to ascertain whether the patient indeed experiences altered sensation signs, and document the findings (Rosen, 2014; Givol et al., 2011; Pogrel, 2007; Juodzbalys et al., 2011; Givol et al., 2010), as a baseline for a rigorous follow-up (Rosen, 2014; Pogrel et al., 2011).

Neurosensory impairment is a complex scenario with diverse manifestations (Pogrel, 2017; Rosen, 2014; Pogrel et al., 2011). Sometimes the clinical manifestation of the nerve injury, such as persistent and long-lasting pain, may be confused with other post-operative symptoms (Rosen, 2014; Gallas-Torreira et al., 2003; Pogrel et al., 2011; Juodzbalys et al., 2011; Polycarpou et al., 2005; Campbell et al., 1990; Cruccu et al., 2010; Fagade \& Wastell, 1990; Meyer \& Bagheri, 2011; Poort et al., 2009). Thus, the practitioner is required to pay his attention to this etiologic 
alternative, especially in cases with persistent symptoms following apparently successful endodontic treatments (Rosen, 2014; Gallas-Torreira et al., 2003; Juodzbalys et al., 2011; Polycarpou et al., 2005; Campbell et al., 1990; Cruccu et al., 2010; Fagade \& Wastell, 1990; Meyer \& Bagheri, 2011; Poort et al., 2009).

The methods used for neurosensory function evaluation differ significantly, extending between basic patient questioning and complex examinations (Kim et al., 2015). However, the fundamental marker of a sensory malfunction is the patient's own subjective complaints (Yatsuhashi et al., 2003; Pogrel, 2007; Juodzbalys et al., 2011; Bennett et al., 1987; Bennett \& Jannetta, 1980). Presently, there is no agreement as to the ideal techniques to assess nerve injury following endodontic treatment. Nevertheless, it is advised that the diagnostic process would be based on clinical sensory testing and complementary objective sensory tests (Pogrel, 2017; Rosen, 2014; Pogrel et al., 2011).

The nature and extent of the neurosensory damage are evaluated using a set of designated clinical tests, each of them aimed to assess specific neural functions (Rosen, 2014; Ghali \& Epker, 1989). The clinical evaluation should start by determining the boundaries of the affected area (Rosen, 2014; Meyer \& Bagheri, 2011). Once the affected area boundaries are determined, the next goal is to define the exact nature and severity of the neurosensory impairment (Rosen, 2014; Meyer \& Bagheri, 2011). In order to increase the objectivity of the evaluations, all tests should be performed by comparing the affected side to the contra-lateral non-involved side, while the patient's eyes are closed, and by using visual analog scale (VAS)-based questions (Rosen, 2014; Pogrel et al., 2011).

The clinical neurosensory testing may be divided into two types: mechanoceptive and nociceptive (Boada et al., 2015), based on the specific stimulated receptors being evaluated (Rosen, 2014; Juodzbalys et al., 2011; Ghali \& Epker, 1989; Boada et al., 2015). Mechanoceptive testing includes clinical tests such as the 'Static light touch' test or the "Two-point discrimination" test (Ghali \& Epker, 1989). Nociceptive testing includes clinical tests such as the "Thermal discrimination" test (Rosen, 2014; Ghali \& Epker, 1989).

Figure $1 \mathrm{a}-\mathrm{f}$ presents a few clinical evaluation methods of a suspected inferior alveolar nerve injury following an endodontic treatment.

Objective sensory tests (Kim et al., 2015; Agbaje et al., 2015) are aimed to avoid a possible bias from the subjectivity of the clinical sensory testing (Rosen, 2014; Fagade \& Wastell, 1990; Bennett et al., 1987; Bennett \& Jannetta, 1980; Agbaje et al., 2015; Barker et al., 1987). "Trigeminal Evoked Potentials (TEP)" and "Quantitative sensory testing (QST)" (Kim et al., 2015) are examples of objective and non-invasive methods to measure peripheral neural function (Kim et al., 2015; Zhao et al., 2017), that may be used as an adjunct in the diagnostic process following trigeminal nerve injuries (Rosen, 2014; Fagade \& Wastell, 1990; Bennett et al., 1987; Bennett \& Jannetta, 1980; Barker et al., 1987).

These evaluation methods may require professional expertise that is beyond the dental practitioner's clinical capacity (Pogrel, 2007; Chaushu et al., 2002; Fagade \& Wastell, 1990; Bennett et al., 1987; Bennett \& Jannetta, 1980; Barker et al., 1987). However, the practitioner needs to be sensitive to the possibility of nerve injury following the endodontic treatment, and should recognize the possible risk factors and clinical manifestations (Pogrel, 2017; Rosen, 2014; Ghali \& Epker, 1989). First and foremost, the practitioner should be able to determine the suspicion of altered sensation, and refer the patient to a specialist if required (Bagheri \& Meyer, 2014), thus enabling a better clinical and medico-legal management (Rosen, 2014; Givol et al., 2011; Givol et al., 2010; Ghali \& Epker, 1989).

\section{Management of endodontic-treatment related nerve injury}

Long-lasting altered sensation as a result of nerve injury during the endodontic treatment may have substantial adverse effects on the patient's quality of life (Pogrel, 2017; Wojtkiewicz et al., 2015). In addition, the iatrogenic origin of these injuries further increases the adverse psychological consequences of these injuries (Pogrel et al., 2011). Therefore, the patient needs emotional support including the receipt of accurate information regarding their state, to align their expectations from the possible treatments and expected prognosis (Rosen, 2014; Scolozzi et al., 2004; Wojtkiewicz et al., 2015).

Several non-surgical and surgical modalities have been recommended for the management of endodontic-related nerve injuries, depending on the specific injury mechanism (Pogrel, 2017; Lampert et al., 2016). However, these modalities are mostly based on case reports and small case-series studies (Rosen et al., 2016). Yet, the collective knowledge from the currently available evidence is that the nerve damage may increase with time (Pogrel, 2017; Rosen et al., 2016). Therefore, in case a nerve injury is suspected, a timely mannered clinical approach is advised in order to minimize long term damage (Rosen, 2014; Rosen et al., 2016; Scolozzi et al., 2004; Shavit \& Juodzbalys, 2014).

Injury of a peripheral nerve may lead to edema and inflammation (Dubovy et al., 2013). Thus, early administration of anti-inflammatory drugs, such as corticosteroids or nonsteroidal anti-inflammatory drugs (NSAIDs) (Rosen, 2014; Pogrel et al., 2011) may be beneficial, even as a preventive approach in the absence of a definitive diagnosis. Consequently, anti-inflammatory drugs were suggested as the primary therapeutic non-invasive management approach (Rosen, 2014; Pogrel, 2007; Juodzbalys et al., 2011; Froes et al., 2009). 

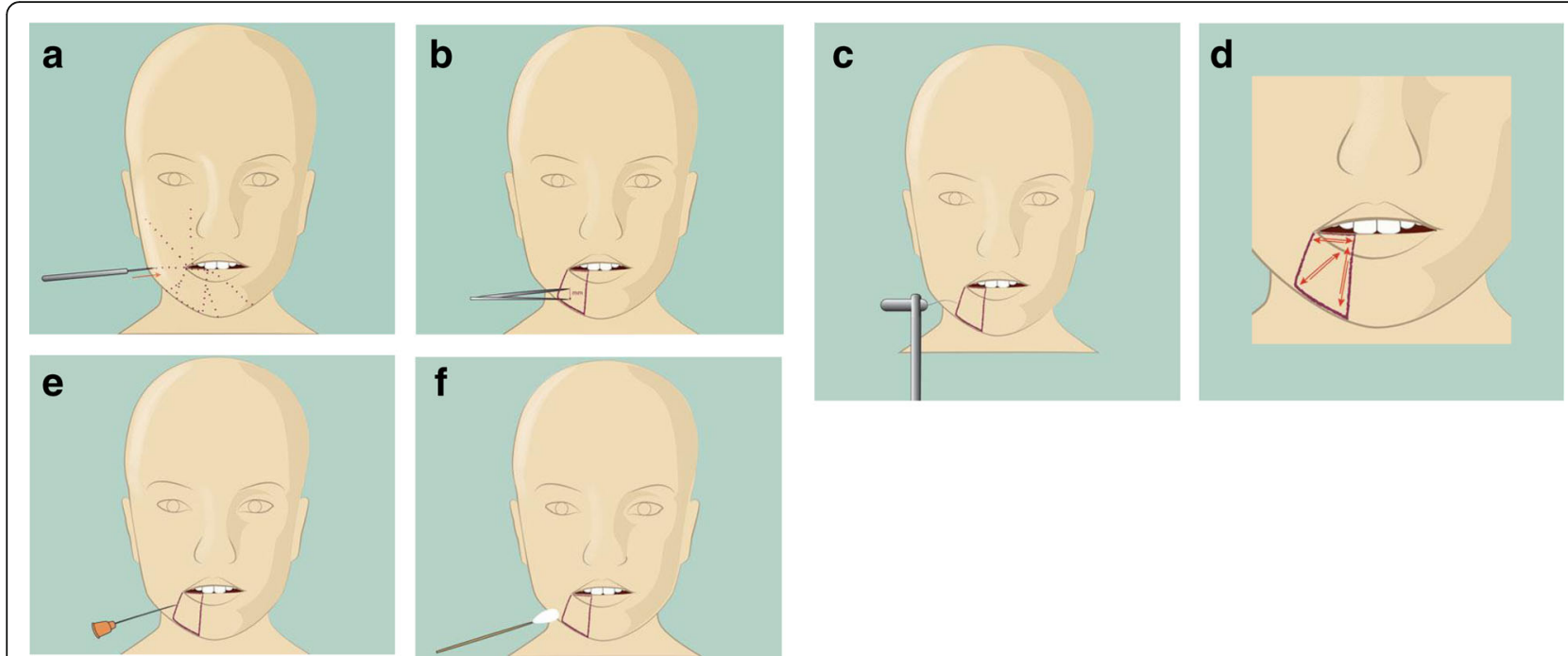

Fig. 1 clinical evaluation methods of a suspected inferior alveolar nerve injury following an endodontic treatment. (Adopted with permission from: Rosen E. Nerve Injury During Endodontic Surgical Procedures. In: Tsesis I, editor. Complications in Endodontic Surgery: Springer-Verlag Berlin Heidelberg; 2014). a Determining the boundaries of the affected area: an explorer is applied with repeated contact points beginning from the outlying non-affected area, toward the internal affected area (arrow). The point in which the patient denotes a change of sensation is registered as the boundary of the affected area; $\mathbf{b}$ Two-point discrimination: measuring the gap at which the patient is able of distinguishing two contact points, with a growing distance between the tweezers arms; c Static light touch: the patient response is assessed while a device holding increasingly firmer monofilaments is applied until the monofilament curves; $\mathbf{d}$ Brush directional stroke: the patient is asked to verify the direction of the stroke while applying brush strokes of a monofilament (arrows); e Pin prick test using a needle to assess the response: sharp, dull or no sensation; $\mathbf{f}$ Thermal discrimination: the patient response is assessed while applying a cotton-tipped applicator sprayed with a topical anesthetic skin refrigerant, or deprived of spray as control

Further non-invasive management modalities that were suggested for cases of persistent peripheral nerve injuries include the use of anti-depressants (Park et al., 2010), cryotherapy-the application of cold for therapeutic purposes (Osunde et al., 2011) - physiologic therapies such as trans-cutaneous electric nerve stimulation (Cotter, 1983; Singla et al., 2011) and low-level laser therapy (Rosen, 2014; Leung et al., 2012).

Certain persistent cases that are not responsive to noninvasive treatments may be referred to neurosurgical procedures (Byun et al., 2016). When such a surgical procedure is indicated, it may be more effective if performed before the setup of a wallerian degeneration (a process in which the axon distal to a site of injury degenerates) about 3 months following the injury (Rosen, 2014; Pogrel, 2007; Juodzbalys et al., 2011; Leung et al., 2012).

Several surgical techniques were suggested in order to treat certain nerve injuries including "external neurolysis" (Joshi \& Rood, 2002), the use of grafts to channel the nerve defect, or direct suturing (Rosen, 2014; Pogrel, 2007; Juodzbalys et al., 2011; Leung et al., 2012). However, the indications and clinical effectiveness of these surgical techniques appear to be variable and poorly documented, mainly in case reports and retrospective studies. In addition, complete recovery of the normal sensation following these surgical procedures is not certain (Rosen, 2014; Leung et al., 2012). It should also be taken into consideration that in many of the cases the altered sensation originally occurred as a result of trauma during the endodontic treatment, and an additional corrective surgical procedure may introduce an additional trauma and inflammation, thus adversely affecting the patient's state (Rosen, 2014; Leung et al., 2012).

Recently (Rosen et al., 2017) it was suggested that modern endodontic surgery that uses magnification and illumination devices to enable a minimally invasive and highly accurate surgical procedure (Taschieri et al., 2010; Tsesis et al., 2009; Tsesis et al., 2013), may be beneficial for patients with certain nerve injuries following endodontic treatment (Tsesis et al., 2014; Rosen et al., 2017). A recent study reported on a case of extruded endodontic materials with ensuing altered sensation, where modern endodontic surgery enabled the removal of the irritating extruded endodontic materials, proper root-end management, the elimination of the altered sensation and the preservation of the natural tooth (Rosen et al., 2017). Another recent study (Tsesis et al., 2014) reported on a case of altered sensation following endodontic treatment of a second mandibular molar that was successfully treated by intentional replantation. It is a relatively conservative procedure, that includes the intentional extraction of a tooth and its re-placement into the alveolar socket after performing a proper root-end management and obturation (Tsesis et al., 2014). With adequate case selection, 
these procedures may provide a predictable outcome and allow the preservation of the tooth (Tsesis et al., 2014; Rosen et al., 2017).

Figure 2 presents an algorithm for the diagnosis and management of suspected nerve injury following an endodontic treatment.

The long-term prognosis of altered sensation following endodontic treatments is not yet fully elucidated (Pogrel, 2017), but it is believed to be related to the type and extent of injury, and to the timing and nature of the therapeutic intervention (Rosen, 2014; Pogrel, 2007; Pogrel et al., 2011; Juodzbalys et al., 2011; Seddon, 1942; Leung et al., 2012).

Recently (Rosen et al., 2016), a comprehensive systematic review of the literature was performed to identify and assess studies that reported on altered sensation following extrusion of root canal filling materials during endodontic treatments, in order to assess possible factors that may affect the prognosis of such cases. Eventually, 28 articles that met the inclusion criteria were assessed. Most of the articles were case reports reporting on a total of 84 patients. It was reported that $91 \%$ of the patients had fully or partially recovered over time. However, in most of the cases that occurred in lower molars, when the root canal obturation was done using paraformaldehyde-containing sealer, or in cases in which an immediate intervention was not performed following the occurrence of the nerve injury, the patients did not fully recover (Rosen et al., 2016).

Therefore, from the currently available endodontic (Rosen et al., 2016) and maxillofacial surgery literature (Shavit \& Juodzbalys, 2014), it appears that many of the patients, especially those with a fairly low extent of injury and who received an appropriate early intervention treatment (Shavit \& Juodzbalys, 2014), did tend to recover with time (Rosen, 2014; Rosen et al., 2016; Pogrel et al., 2011; Shavit \& Juodzbalys, 2014). However, some of the patients may suffer from long-term or even permanent disability,

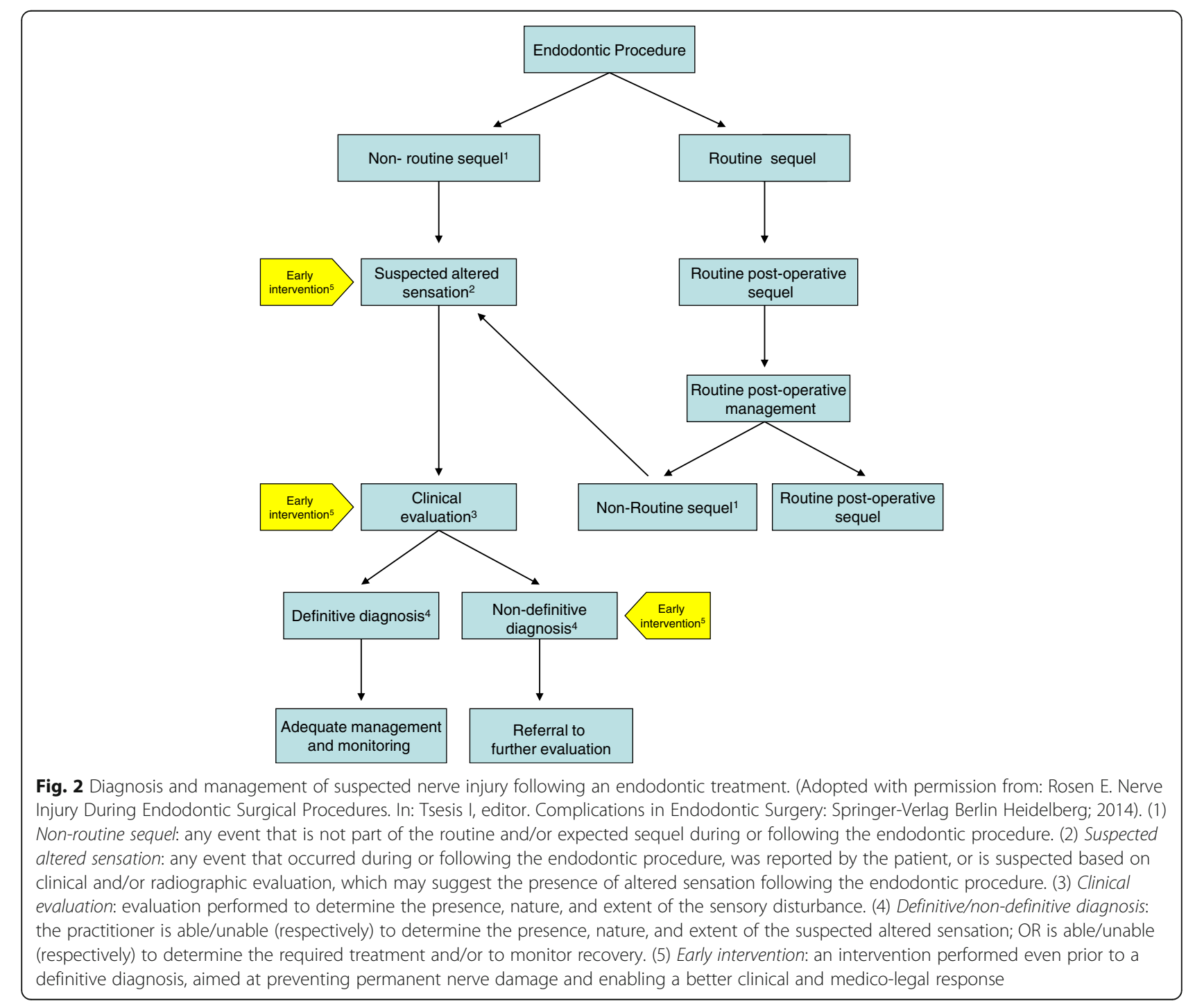


with significant medical and medico-legal consequences (Givol et al., 2011; Givol et al., 2010) and substantial negative effects on their quality of life (Pogrel, 2017; Rosen, 2014; Pogrel, 2007; Pogrel et al., 2011; Juodzbalys et al., 2011; Seddon, 1942; Leung et al., 2012). Pogrel et al. (Pogrel et al., 2011) reported that among patients who suffered from long-term altered sensation following trigeminal nerve injury, many reported on eating disorders (43\%), speech difficulties (38\%), depression (37\%), relationship effects (14\%), and adverse effects on employment (13\%) (Pogrel et al., 2011).

\section{Conclusions}

Vigorous preventive measures and a timely mannered management approach are the most proficient measures to reduce the risk of endodontic-treatment related nerve injuries and to prevent long-lasting impairment.

The diagnosis of a nerve injury requires a combination of a thorough anamnesis, a proper clinical evaluation and an adjunct radiographic evaluation when indicated. The nature and severity of the neurosensory damage are evaluated using a set of designated subjective and objective evaluations.

When a nerve injury is suspected, early intervention by the prescription of anti-inflammatory drugs may be beneficial. Certain persistent cases may be treated surgically. Modern endodontic surgery may enable a minimally invasive and highly accurate surgical procedure, and with adequate case selection may provide a predictable outcome and allow the preservation of the tooth.

\section{Abbreviations}

CBCT: Cone beam computed tomography; NSAIDs: Nonsteroidal antiinflammatory drugs; QST: Quantitative sensory testing; TEP: Trigeminal evoked potentials; VAS: Visual analog scale

\section{Acknowledgements}

The author would like to thank Mugridge Robyn for her assistance in proofreading.

\section{Funding}

No funding.

\section{Availability of data and materials}

Data sharing not applicable to this article as no datasets were generated or analyzed during the current study.

\section{Authors' contributions}

ER prepared the manuscript and approved the final manuscript.

\section{Authors' information}

ER is the editor-in-chief of Evidence-Based Endodontics journal.

\section{Ethics approval and consent to participate}

Not applicable.

\section{Consent for publication}

Not applicable.

\section{Competing interests}

The author declares that he has no competing interests.

\section{Publisher's Note}

Springer Nature remains neutral with regard to jurisdictional claims in published maps and institutional affiliations.

Received: 27 September 2017 Accepted: 30 November 2017

Published online: 12 December 2017

\section{References}

Agbaje JO, Salem AS, Lambrichts I, Jacobs R, Politis C. Systematic review of the incidence of inferior alveolar nerve injury in bilateral sagittal split osteotomy and the assessment of neurosensory disturbances. Int J Oral Maxillofac Surg. 2015;44(4):447-51.

Alves FR, Coutinho MS, Goncalves LS. Endodontic-related facial paresthesia: systematic review. J Can Dent Assoc. 2014;80:e13.

Bagheri SC, Meyer RA. When to refer a patient with a nerve injury to a specialist. J Am Dent Assoc. 2014;145(8):859-61.

Barker GR, Bennett AJ, Wastell DG. Applications of trigeminal somatosensory evoked potentials (TSEPS) in oral and maxillofacial surgery. Br J Oral Maxillofac Surg. 1987;25(4):308-13.

Bennett AJ, Wastell DG, Barker GR, Blackburn CW, Rood JP. Trigeminal somatosensory evoked potentials. A review of the literature as applicable to oral dysaesthesias. Int J Oral Maxillofac Surg. 1987;16(4):408-15.

Bennett MH, Jannetta PJ. Trigeminal evoked potentials in humans. Electroencephalogr Clin Neurophysiol. 1980;48(5):517-26.

Bjorndal L, Reit C. Endodontic malpractice claims in Denmark 1995-2004. Int Endod J. 2008:41(12):1059-65.

Boada MD, Gutierrez S, Aschenbrenner CA, Houle TT, Hayashida K, Ririe DG, et al. Nerve injury induces a new profile of tactile and mechanical nociceptor input from undamaged peripheral afferents. J Neurophysiol. 2015;113(1):100-9.

Bornstein MM, Lauber R, Sendi P, von Arx T. Comparison of periapical radiography and limited cone-beam computed tomography in mandibular molars for analysis of anatomical landmarks before apical surgery. J Endod. 2011;37(2):151-7.

Byun SH, Kim SS, Chung HJ, Lim HK, Hei WH, Woo JM, et al. Surgical management of damaged inferior alveolar nerve caused by endodontic overfilling of calcium hydroxide paste. Int Endod J. 2016;49(11):1020-9.

Campbell RL, Parks KW, Dodds RN. Chronic facial pain associated with endodontic therapy. Oral Surg Oral Med Oral Pathol. 1990;69(3):287-90.

Chaushu G, Taicher S, Halamish-Shani T, Givol N. Medicolegal aspects of altered sensation following implant placement in the mandible. Int J Oral Maxillofac Implants. 2002;17(3):413-5.

Chong BS, Gohil K, Pawar R, Makdissi J. Anatomical relationship between mental foramen, mandibular teeth and risk of nerve injury with endodontic treatment. Clin Oral Investig. 2017;21(1):381-7.

Cotter DJ. Overview of transcutaneous electrical nerve stimulation for treatment of acute postoperative pain. Med Instrum. 1983;17(4):289-92.

Cruccu G, Sommer C, Anand P, Attal N, Baron R, Garcia-Larrea L, et al. EFNS guidelines on neuropathic pain assessment: revised 2009. Eur J Neurol. 2010; 17(8):1010-8.

Divya KS, Moran NA, Atkin PA. Numb chin syndrome: a case series and discussion. Br Dent J. 2010;208(4):157-60.

Dubovy P, Jancalek R, Kubek T. Role of inflammation and cytokines in peripheral nerve regeneration. Int Rev Neurobiol. 2013;108:173-206.

Escoda-Francoli J, Canalda-Sahli C, Soler A, Figueiredo R, Gay-Escoda C. Inferior alveolar nerve damage because of overextended endodontic material: a problem of sealer cement biocompatibility? J Endod. 2007:33(12):1484-9.

Fagade 00, Wastell DG. Trigeminal somatosensory evoked potentials: technical parameters, reliability and potential in clinical dentistry. J Dent. 1990;18(3):137-41.

Froes FG, Miranda AM, Abad Eda C, Riche FN, Pires FR. Non-surgical management of paraesthesia and pain associated with endodontic sealer extrusion into the mandibular canal. Aust Endod J. 2009;35(3):183-6.

Gallas-Torreira MM, Reboiras-Lopez MD, Garcia-Garcia A, Gandara-Rey J. Mandibular nerve paresthesia caused by endodontic treatment. Med Oral. 2003:8(4):299-303.

Garisto GA, Gaffen AS, Lawrence HP, Tenenbaum HC, Haas DA. Occurrence of paresthesia after dental local anesthetic administration in the United States. Am Dent Assoc. 2010;141(7):836-44.

Ghali GE, Epker BN. Clinical neurosensory testing: practical applications. J Oral Maxillofac Surg. 1989;47(10):1074-8. 
Givol N, Rosen E, Bjorndal L, Taschieri S, Ofec R, Tsesis I. Medico-legal aspects of altered sensation following endodontic treatment: a retrospective case series. Oral Surg Oral Med Oral Pathol Oral Radiol Endod. 2011;112(1):126-31.

Givol N, Rosen E, Taicher S, Tsesis I. Risk management in endodontics. J Endod. 2010; 2010 Jun;36(6):982-984.

Givol N, Taicher S, Halamish-Shani T, Chaushu G. Risk management aspects of implant dentistry. Int J Oral Maxillofac Implants. 2002;17(2):258-62.

Grotz KA, Al-Nawas B, de Aguiar EG, Schulz A, Wagner W. Treatment of injuries to the inferior alveolar nerve after endodontic procedures. Clin Oral Investig. 1998;2(2):73-6.

Guivarc'h M, Ordioni U, Ahmed HM, Cohen S, Catherine JH, Bukiet F. Sodium hypochlorite accident: a systematic review. J Endod. 2017;43(1):16-24.

Hillerup S, Jensen R. Nerve injury caused by mandibular block analgesia. Int J Oral Maxillofac Surg. 2006;35(5):437-43.

Joshi A, Rood JP. External neurolysis of the lingual nerve. Int J Oral Maxillofac Surg. 2002;31(1):40-3.

Juodzbalys $\mathrm{G}$, Wang $\mathrm{H}$, Sabalys $\mathrm{G}$. Injury of the inferior alveolar nerve during implant placement: a literature review. J Oral Maxillofac Res. 2011;2(1):e1.

Kamburoglu K, Kilic C, Ozen T, Yuksel SP. Measurements of mandibular canal region obtained by cone-beam computed tomography: a cadaveric study. Oral Surg Oral Med Oral Pathol Oral Radiol Endod. 2009;107(2):e34-42.

Kim S, Kratchman S. Modern endodontic surgery concepts and practice: a review. J Endod. 2006;32(7):601-23.

Kim TS, Caruso JM, Christensen H, Torabinejad M. A comparison of cone-beam computed tomography and direct measurement in the examination of the mandibular canal and adjacent structures. J Endod. 2010;36(7):1191-4.

Kim YK, Yun PY, Kim JH, Lee JY, Lee W. The quantitative sensory testing is an efficient objective method for assessment of nerve injury. Maxillofac Plast Reconstr Surg. 2015;37:13. 1-7

Kovisto T, Ahmad M, Bowles WR. Proximity of the mandibular canal to the tooth apex. J Endod. 2011;37(3):311-5.

Lampert RC, Nesbitt TR, Chuang SK, Ziccardi VB. Management of endodontic injuries to the inferior alveolar nerve. Quintessence Int. 2016;47(7):581-7.

Leung YY, Fung PP, Cheung LK. Treatment modalities of neurosensory deficit after lower third molar surgery: a systematic review. J Oral Maxillofac Surg. 2012;70(4):768-78.

Meyer RA, Bagheri SC. Clinical evaluation of peripheral trigeminal nerve injuries. Atlas Oral Maxillofac Surg Clin North Am. 2011;19(1):15-33.

Moiseiwitsch JR. Avoiding the mental foramen during periapical surgery. J Endod. 1995:21(6):340-2

Osunde OD, Adebola RA, Omeje UK. Management of inflammatory complications in third molar surgery: a review of the literature. Afr Health Sci. 2011;11(3):530-7.

Park JH, Lee SH, Kim ST. Pharmacologic management of trigeminal nerve injury pain after dental implant surgery. Int J Prosthodont. 2010;23(4):342-6.

Patel S. New dimensions in endodontic imaging: part 2. Cone beam computed tomography. Int Endod J. 2009;42(6):463-75.

Pogrel MA. Damage to the inferior alveolar nerve as the result of root canal therapy. J Am Dent Assoc. 2007;138(1):65-9.

Pogrel MA. Nerve damage in dentistry. Gen Dent. 2017;65(2):34-41.

Pogrel MA, Jergensen R, Burgon E, Hulme D. Long-term outcome of trigeminal nerve injuries related to dental treatment. J Oral Maxillofac Surg. 2011;69(9):2284-8.

Polycarpou N, Ng YL, Canavan D, Moles DR, Gulabivala K. Prevalence of persistent pain after endodontic treatment and factors affecting its occurrence in cases with complete radiographic healing. Int Endod J. 2005:38(3):169-78.

Poort LJ, van Neck JW, van der Wal KG. Sensory testing of inferior alveolar nerve injuries: a review of methods used in prospective studies. J Oral Maxillofac Surg. 2009;67(2):292-300.

Rosen E. Nerve injury during endodontic surgical procedures. In: Tsesis I, editor. Complications in endodontic surgery. Berlin Heidelberg: Springer-Verlag; 2014. p. 137-51.

Rosen E, Allareddy V, Tsesis I. Case selection for the use of cone beam computed tomography in dentistry based on diagnostic efficacy and risk assessment. In: Rosen E, Nemcovsky CE, Tsesis I, editors. Evidence-based decision making in dentistry. Switzerland: Springer International Publishing; 2017. p. 97-108.

Rosen E, Goldberger T, Taschieri S, Del Fabbro M, Corbella S, Tsesis I. The prognosis of altered sensation after extrusion of root canal filling materials: a systematic review of the literature. J Endod. 2016;42(6):873-9.

Rosen E, Goldberger T, Taschieri S, Del-Fabbro M, Tsesis I. Modern surgical endodontic treatment of altered sensation following extrusion of endodontic filling materials. Refuat Hapeh Vehashinayim. 2017;1:17-25.
Rosen E, Taschieri S, Del Fabbro M, Beitlitum I, Tsesis I. The diagnostic efficacy of cone-beam computed tomography in endodontics: a systematic review and analysis by a hierarchical model of efficacy. J Endod. 2015;41(7):1008-14.

Scolozzi P, Lombardi T, Jaques B. Successful inferior alveolar nerve decompression for dysesthesia following endodontic treatment: report of 4 cases treated by mandibular sagittal osteotomy. Oral Surg Oral Med Oral Pathol Oral Radiol Endod. 2004;97(5):625-31.

Seddon HJ. A classification of nerve injuries. Br Med J. 1942;2(4260):237-9.

Seddon HJ, Medawar PB, Smith H. Rate of regeneration of peripheral nerves in man. J Physiol. 1943;102(2):191-215.

Shavit I, Juodzbalys G. Inferior alveolar nerve injuries following implant placement-importance of early diagnosis and treatment: a systematic review. J Oral Maxillofac Res. 2014;5(4):e2.

Simonton JD, Azevedo B, Schindler WG, Hargreaves KM. Age- and gender-related differences in the position of the inferior alveolar nerve by using cone beam computed tomography. J Endod. 2009;35(7):944-9.

Singla S, Prabhakar V, Singla RK. Role of transcutaneous electric nerve stimulation in the management of trigeminal neuralgia. J Neurosci Rural Pract. 2011;2(2):150-2.

Taschieri S, Del Fabbro M, Weinstein T, Rosen E, Tsesis I. Magnification in modern endodontic practice. Refuat Hapeh Vehashinayim. 2010;27(3):18-22. 61

Tilotta-Yasukawa F, Millot S, El Haddioui A, Bravetti P, Gaudy JF. Labiomandibular paresthesia caused by endodontic treatment: an anatomic and clinical study. Oral Surg Oral Med Oral Pathol Oral Radiol Endod. 2006;102(4):e47-59.

Tsesis I, Faivishevsky V, Kfir A, Rosen E. Outcome of surgical endodontic treatment performed by a modern technique: a meta-analysis of literature. J Endod. 2009;35(11):1505-11.

Tsesis I, Rosen E, Taschieri S, Telishevsky Strauss Y, Ceresoli V, Del Fabbro M. Outcomes of surgical endodontic treatment performed by a modern technique: an updated meta-analysis of the literature. J Endod. 2013; 39(3):332-9.

Tsesis I, Taschieri S, Rosen E, Corbella S, Del Fabbro M. Treatment of paraesthesia following root canal treatment by intentional tooth replantation: a review of the literature and a case report. Indian J Dent Res. 2014;25(2):231-5.

Wojtkiewicz DM, Saunders J, Domeshek L, Novak CB, Kaskutas V, Mackinnon SE. Social impact of peripheral nerve injuries. Hand (N Y). 2015;10(2):161-7.

Yatsuhashi T, Nakagawa K, Matsumoto M, Kasahara M, Igarashi T, Ichinohe T, et al. Inferior alveolar nerve paresthesia relieved by microscopic endodontic treatment. Bull Tokyo Dent Coll. 2003;44(4):209-12.

Zhao YX, Miao SH, Tang YZ, He LL, Yang LQ, Ma Y, et al. Trigeminal somatosensoryevoked potential: a neurophysiological tool to monitor the extent of lesion of ganglion radiofrequency thermocoagulation in idiopathic trigeminal neuralgia: a case-control study. Medicine (Baltimore). 2017;96(3):e5872

\section{Submit your manuscript to a SpringerOpen ${ }^{\circ}$ journal and benefit from:}

- Convenient online submission

- Rigorous peer review

- Open access: articles freely available online

- High visibility within the field

- Retaining the copyright to your article

Submit your next manuscript at $>$ springeropen.com 